\title{
A SURVEY TO IDENTIFY FACILITY REQUIREMENTS IN THE ADMINISTRATIVE WORKPLACE
}

\author{
Prima Vitasari $^{1^{*}}$, Dayal Gustopo ${ }^{2}$, Sri Indriani ${ }^{3}$, Suriya Kumar Sinnadurai ${ }^{4}$ \\ 1,2,3 Industrial Engineering, National Institute of Technology Malang, Indonesia \\ ${ }^{4}$ Centre for Modern Language and Human Sciences, Universiti Malaysia Pahang, Malaysia
}

*Corresponding Email: primavitasari19@gmail.com

\begin{abstract}
A flexible work surrounding is recommended for the comfort of employees while doing their activities. Workplace design affects the individual who work inside it. Previous researches had revealed that physical elements in workplace affected employees' creativity. From these descriptions this research then making identification to physical elements that placed inside workplace of administration staffs. 150 respondents have been participated in this survey. Questionnaires of this research have 13 questions where some of the questions asking about computer set also type of office equipment that employee usually use in their work. The result of this research showed that most employees have sufficient work facility which is computer set with LCD monitor where its screen size is adjusted according to the work demand (19 inch), and computer lifespan is relatively ranging of five years. While type identification and computer function consider to be appropriate for their job desk. From placement or setting of work facilities gives description that average employees want computer placed at the center of desk and put other work equipment on the right side of the desk. The result of this survey is expected able to give significant contribution to workplace design that suitable for administration staff.
\end{abstract}

Keywords: Workplace, Survey, Facility, Office Equipment

\section{Introduction}

Work can be identified as series of routine task or repetitive of work that people do. Based on standard and historical data of a work that is taken from routine or creative result. The previous researches showed that percentage of work that basically has routine and repetitive nature is office work, accounting and administrative work [1]. Aside from it, considering the importance of routinely inside organization and work surroundings these days requires sort of creativity and innovation. Therefore, the most important function of work surroundings is as a support to dynamic organizational changes and rapid technology development. There are factors related to work surrounding such as innovative communication system, technology improvement, e-market development, virtual reality, and choices or other alternative work model. These factors can play important part in supporting creativity inside an organization. Creativity in work can accommodate the fast-changing technology, similar to many organizations that shifting to work team version in their work surroundings. Becker [9] suggested that work surroundings will support working style of people, and a flexible workplace is more recommended for gaining employee's satisfaction in doing their work.
Thus, work design and its placement that less suitable had tendency to affect health, comfort and welfare of every individual. It leads to productivity and creativity decreases from employees. From several related researches explained by some experts told the focus of assessing physical elements from workplace with its inside elements are influencing the creativity side of the employees [6; 7]. Other researches are revealing about direct and indirect effects from physical work to people creativity through influence to employee's mood when working [5]. Starting from these findings then this research will make an identification to gain data about the necessity of facility inside workplace. Next, the result of identification will be used to make workplace design that putting concern on the ergonomic side for administration staff.

\section{Workplace Facility}

To perform a work as administration staff with computer as working media needs certain understanding related to this appliance. Such as color application to computer screen, Jeffrey et al [3] said that visual system from human are only able to see around 350.000 colors. There is one combination that offers maximum contrast to white background like paperwork. Where some 
similar researches also show result of better display or better eyesight that increasing work efficiency [3].

Previous study explains that speed in reading is proven to be increase from $4,1 \%$ to $19,9 \%$ depends on computer screen type [4]. For employee with adequate eyesight can read faster with better picture quality. A study Jeffrey [3] explain that individual with worse eyesight will able to perform better work performance by ways that can increase their eyesight capability. This description explains about demand or needs to give eye maintenance/treatment for people who work using computer like administration staff.

Several offices have made visual work performance manifestation by using newer appliance which is LCD monitor technology. LCD possess many advantages such as lighter weight and smaller size, easier to put or placed on the table, less electrify, generating fewer electromagnetic radiation, and having smoother pixel formation [3]. Unfortunately, better brightness feature in LCD monitor screen can gives negative impact when it is not correctly controlled. Aside from it, pixel in LCD monitor is very sharp and clear until it seen as dot matrix pattern rather than smooth letters. From one study that compares computation work performance between LCD monitor and CRT monitor resulted in LCD monitor had better work performance [2]. However, for employees who have difficulty with screen lighting, switching to LCD screen is not an effective way in solving the problem.

Another information comes from one research that recommends check up to computer user by adding detail history of symptom, work nature of computer, position and work range to screen and other materials, also another visual characteristics from its work surroundings such as lighting and reflection, assessment of accommodative ability (focus to human eye), assessment of ocular coordination, bias determination for required eyesight in computer workstation, occupancy lens design when necessary, and counseling about visual environment in the workstation [3].

\section{Method}

This research uses survey as data collection method with questionnaires as its instrument. 150 employees who work in administration department had participated in this research. There are seventy-eight men participants and seventy-two women participants. Questionnaires' spreading is conducted in random to all participants and time required for this survey was two months.

Questionnaires as research instrument was designed based on related references from several prior researches such as computer [3], equipment [9], and workplace facilities [9]. There are 13 questions with three different optional answers depending on the type of questions. Like question number one where it asks about computer screen that the employees want in their workplace, with answer choices are LCD monitor, tube monitor, or laptop. aside from question about computer appliances that mostly use by administrative staff in working, this survey also asking to participants about table work arrangement, other work appliances that employees usually need in their work also another equipment such as bookshelf and ornaments inside their workplace.

Data analysis technique that employed in this research is statistic descriptive analysis to find demographic data of respondents and to see frequency for each indicator. Next, correlation analysis is used to gain coefficient value of relation among variables.

\section{Result}

\subsection{Demographic of Respondents}

Table 1 presents information about respondent's demographic where $\mathrm{N}$ amount is 150 respondents. It divided into three categories which are gender, status of employees, and contract (occupation) time. For gender category gained 78 male respondents and 72 female respondents. Employees' status was 38 employees of civil servants and 112 employees of private sector. Contract/occupation time categorized into 5 levels which are: less than 5 years with 69 employees, 5 - 10 years with 19 employees, $10-15$ years with 19 employees, 15 - 20 years with 7 employees, and more than 20 years with 25 employees. The tabulation result between frequency and percentage is obtained by using statistic descriptive analysis presented below: 
Table 1. Information of Respondents Demographic

\begin{tabular}{llll}
\hline \multirow{2}{*}{ Category } & Description & Frequency & Percentage (\%) \\
\hline \multirow{2}{*}{ Gender } & Male & 78 & 52 \\
\cline { 2 - 4 } & Female & 72 & 48 \\
\hline \multirow{2}{*}{ Employees' Status } & Civil Servant & 38 & 25,3 \\
\cline { 2 - 4 } & Private sector & 112 & 74,7 \\
\hline \multirow{3}{*}{ Contract/Occupation Time } & $<5$ years & 69 & 46 \\
\cline { 2 - 4 } & 5-10 years & 30 & 20 \\
\cline { 2 - 4 } & $10-15$ years & 19 & 12.7 \\
\cline { 2 - 4 } & $15-20$ years & 7 & 4.7 \\
\cline { 2 - 4 } & $>20$ years & 25 & 16.7 \\
\hline
\end{tabular}

$* N=150$

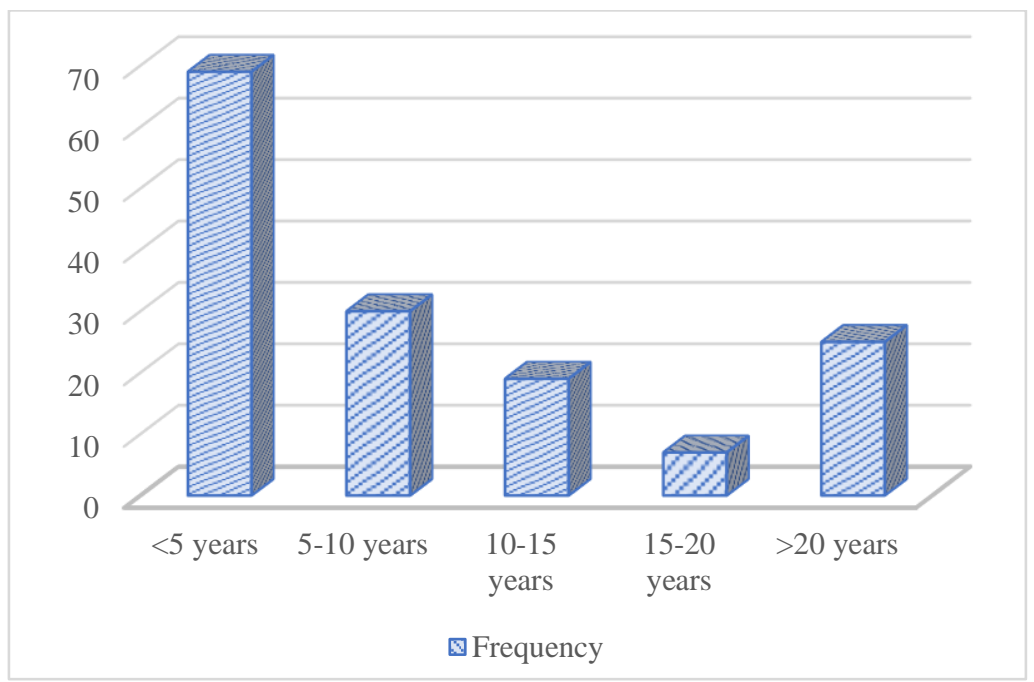

Figure 1. The Description of Employee Period

Contract time of employees is clarified by displaying Figure 1 as description of contract time respondents who join this survey. From the picture above explains that contract time really gives impact to this research result. Where employees who, in average has contract time in minimum time of 3 years up to maximum time of 45 years have contributed in identify work facilities that they have been used in work as administration staff. Therefore, it is expected that this result will give significant contribution for choosing the suitable design workplace for employees.

\subsection{The Comparison between Facility Uses Today with Facility that Needed}

The result from comparison of computer facility that used by employees and computer facility that needed by them is showing that computer shape used by average employees are ranging from LCD computer (101 respondents), laptop (37 respondents), and CRT/tube computer (12 respondents). The computer type that employees wanted are: LCD computer (95 percent respondents), laptop (rising number up to 49 respondents because it is practical and mobile), and CRT/tube computer (only 6 respondents).

Where the screen size from computer monitor that employees use today are 15 inch (61 respondents), 19 inch (70 respondents), and 24 inch (19 respondents). The screen size of computer monitor that expected by majority of employees are: 19 inch (86 respondents), 15 inch (54 respondents), and the rest choose 24 -inch monitor screen (10 respondents).

The comparison of monitor lifespan that has been used today and monitor lifespan that expected are 77 respondents using computer with 
lifespan less than 5 years, 53 respondents are using computer with lifespan $5-10$ years, and 20 respondents are using computer with lifespan more than 10 years. Then, data of computer lifespan that employees expected are 72 respondents want their computers changed every 5 years, 71 respondents want their computers replaced after 10 years, and the rest 7 respondents wish that computers in their workplace need to be replaced every $5-10$ years.
From the explanation above is showing that in average, employees had already received decent facilities of computer set, not only in form of LCD computers but also the screen size (19-inch) are adequate to fulfill their work demand, and their computers relatively good where computer lifespan are ranging about 5 years. Table 2 presents description of computer facility as below.

Table 2. Description of Facility of Computer

\begin{tabular}{|c|c|c|c|c|c|c|}
\hline \multirow{2}{*}{ Category } & \multicolumn{3}{|c|}{ Computer Uses Today } & \multicolumn{3}{|c|}{ Computer Needed } \\
\hline & Description & Frequency & Percentage & Description & Frequency & Percentage \\
\hline \multirow{3}{*}{$\begin{array}{l}\text { Computer } \\
\text { Shape }\end{array}$} & LCD Computer & 101 & 67.3 & LCD Computer & 95 & 63.3 \\
\hline & $\begin{array}{l}\text { CRT/Tube } \\
\text { Computer }\end{array}$ & 12 & 8 & $\begin{array}{l}\text { CRT/Tube } \\
\text { Computer }\end{array}$ & 6 & 4 \\
\hline & Laptop & 37 & 24.7 & Laptop & 49 & 32.7 \\
\hline \multirow{3}{*}{$\begin{array}{l}\text { Screen } \\
\text { Size }\end{array}$} & 15 inches & 61 & 40.6 & 15 inches & 54 & 36 \\
\hline & 19 inches & 70 & 46.7 & 19 inches & 86 & 57.3 \\
\hline & 24 inches & 19 & 12.7 & 24 inches & 10 & 6.7 \\
\hline \multirow{3}{*}{$\begin{array}{l}\text { Computer } \\
\text { Lifespan }\end{array}$} & $<5$ years & 77 & 13.3 & $<5$ years & 72 & 48 \\
\hline & $5-10$ years & 53 & 35.3 & $5-10$ years & 7 & 47.3 \\
\hline & $>10$ years & 20 & 51.4 & $>10$ years & 71 & 4.7 \\
\hline
\end{tabular}

$* N=150$

\subsection{Type and Function of Computer According to Administration Staff}

Next explanation below is result research about type and function of computer according to administration staff. This description is important for knowing the expectation of employees about kinds of work equipment that they expected so it will be suitable with their work as administrative staff. Survey of this research resulted in form of employees' responses about computer type with detail of 85 respondents are using workstation computer type, 45 respondents are using laptop computer type, and 20 respondents are using server computer type. While for the computer function shows that almost 100 percent or 148 respondents using their computers for work, and the rest of 2 respondents said that 1 respondent is using computer for entertaining him/her and 1 respondent is using computer only for workplace accessory. From this analysis the researcher obtain result that type and function of computers for administration staff are appropriate with their necessity. These facilities also had been used in proper way. Table 3 will present the result below.

Table 3. Responses about Type and Function of Computer

\begin{tabular}{llcc}
\hline \multicolumn{1}{c}{ Category } & \multicolumn{1}{c}{ Description } & Frequency & Persentage \\
\hline Computer Type & Workstation & 85 & 13.3 \\
\cline { 2 - 4 } & Laptop & 45 & 30 \\
\cline { 2 - 4 } & Server & 20 & 56.7 \\
\hline \multirow{2}{*}{ Computer Function } & Finishing Work & 148 & 66.7 \\
\cline { 2 - 4 } & Entertainment & 1 & 0.7 \\
\cline { 2 - 4 } & Accessory & 1 & 0.7 \\
& & &
\end{tabular}

$* N=150$ 


\subsection{The Placement of Work Facilities inside Workplace}

Work facilities often placed without any standard arrangement. Employees just put it based on their own comfort or follow design of their workplace. Result survey in this research is identifying work facilities arrangement that in accord to the wish from majority employees. 150 respondents are representing all employees' expectation in arranging the place of their work facilities. Next description is detail result from computer arrangement or placement inside their workplace. There are 62 respondents who want to place their computer at the center, 48 respondents want to place their computer at the left side, and the rest 40 respondents want to place their computer at the right side. While for the arrangement of another office appliance, they gave responses as follow: 77 respondents put their appliances at the right side, 52 respondents put their appliances at the left side, and 21 other respondents put their appliances at the center. Reason for majority respondents is when computer placed in the left side of the desk then other office appliances will be put at the right side. Therefore, from ergonomic side employee's movement range in using all office facilities is calculated for their comfort. These explanations are put inside Table 4 that shows result below.

Table 4. The Description of Work Facility Placement

\begin{tabular}{|c|c|c|c|}
\hline Category & Description & Frequency & Percentage \\
\hline \multirow[t]{3}{*}{ Computer placement } & Right side of the desk & 40 & 32 \\
\hline & Left side of the desk & 48 & 26.7 \\
\hline & Center of the desk & 62 & 41.3 \\
\hline \multirow{3}{*}{$\begin{array}{l}\text { Another } \\
\text { Appliances }\end{array}$} & Right side of the desk & 77 & 51.3 \\
\hline & Left side of the desk & 52 & 34.7 \\
\hline & Center of the desk & 21 & 14 \\
\hline
\end{tabular}

$* N=150$

\section{Conclusions}

Work is series of routine and repeated tasks that conducted by people. Several supporting factors in work are related to the usage of technology equipment such as computer. Work as administration staff is really connected with the usage of this facility in doing their daily job. For employees which average have contract time from $3-45$ years had been contributed in identifying facilities in their workplace. From all description above, the researcher can draw a summary that work facility (computer) in average is sufficient as employee's expectation. Facilities has been used properly to support work accomplishment. For its placement, it also considers the ergonomic side by observing employees' responses while using this work facility that already counted for their comfort in their work surrounding. Finally, these are the explanation about identification result to work facilities that researcher hope be able to give significant contribution for preparing the suitable workplace design.

\section{References}

[1] T. Betsch, S. Haberstroh, A. Glöckner, T. Haar, and K. Fiedler. (2001). The effects of routine strength on adaptation and

[2] information search in recurrent decision making, Organizational Behavior and Human Decision Processes 84(1), 23-53.

[3] M. Ziefle. (1998). Effects of display resolution on visual performance. Human Factors 40(4), 554-568.

[4] R. A. Jeffrey. (2007). Visual ergonomics in the workplace. AAOHN Journal 55(10), 414-420.

[5] J. E. Sheedy, and M. McCarthy. (1994). Reading performance and visual comfort with scale to gray compared with black and white scanned print. Displays 15(1), 27-30.

[6] T. Kristensen. (2004). The physical context of creativity. Creativity and Innovation Management 13(2), 89-96.

[7] J. M. McCoy and G. W. Evans. (2002). The potential role of the physical environment in fostering creativity. Creativity Research Journal 14(3/4), 409-426. 
[8] Y. Martens. (2011). Creative workplace: instrumental and symbolic support for creativity. Facilities 29 (1/2), 63-79.

[9] F. Becker. (2002). Improving organizational performance by exploiting workplace flexibility. Journal of Facilities Management 1(2), 154-162. 